\title{
PENGARUH SELF AFFIRMATION TERHADAP KEPERCAYAAN DIRI LANSIA (Studi DiUnit Pelaksana Teknis Pelayanan Sosial Tresna Werdha Kabupaten Jombang Tahun 2017)
}

\author{
Abdul Rahman ${ }^{1}$ Inayatur Rosyidah ${ }^{2}$ Yayat Supriyatna $^{3}$ \\ ${ }^{123}$ STIKes Borneo Cendekia Medika Pangkalan Bun \\ ${ }^{1}$ email : abdulrahman@gmail.com, ${ }^{2}$ email : inrosyi@ gmail.com, ${ }^{3}$ email : \\ supriyatnayayat628@gmail.com
}

\begin{abstract}
ABSTRAK
Self affirmation merupakan teknik pemprogram diri dalam meningkatkan kepercayaan diri. Kepercayaan diri merupakan bagaimana individu percaya dan yakin pada kemampuan diri, sehingga mampu mengembangkan kesadaran diri berfikir positif dan mandiri. Semakin seseorang berusia lanjut menutup diri, semakin pasif pula perilaku emosional. Kurangnya rasa percaya diri menjadi penyebab emosi exstreme yang dapat mengarah pada depresi, percobaan bunuh diri, penyakit fisik dan mental. Tujuan penelitian ini adalah menganalisis pengaruh self affirmation terhadap kepercayaan dirilansia di Unit Pelaksana Teknis Pelayanan Sosial Tresna Werdha Kabupaten Jombang.Penelitian ini menggunakan rancangan penelitian pre eksperimental dengan pendekatan one groupprestest - posttest, populasi penelitian ini sejumlah 70 lansia, dengan sampel 60 lansia menggunakan simple random sampling. Variabel independent penilitian ini adalah self affirmation dan variabel dependent penelitian ini adalah kepercayaan diri lansia. Alat ukur yaitu kuesioner, kemudian pengolahan data mulai editing, coding, scoring dan tabulating, dandianalisis menggunakan Uji Wilcoxon.Hasil penelitian menunjukkan bahwa dari60 lansia sebelum pemberian self affirmation. Kepercayaan diri, kurang 2 lansia (3,3\%), sedang 30 lansia(30\%), tinggi 28 lansia $(46,7 \%)$ dan setelah pemberian self affirmation kepercayaan diri, kurang 1 lansia $(1,7 \%)$, sedang 24 lansia $(40,0 \%)$, tinggi35 lansia $(58,3 \%)$. Hasil uji wilcoxon 0,0012 yang menunjukan bahwa nilai $\mathrm{p}<0,05$ maka $\mathrm{H} 1$ diterima.Kesimpulanya adalah ada pengaruh self affirmation terhadap kepercayaan diri lansiadi Unit Pelaksana TeknisPelayanan Sosial Tresna Werdha Jombang.
\end{abstract}

Kata kunci: Kepercayaan diri, lansia, self affirmation

\section{THE INFLUENCE OF SELF AFFIRMATION AGAINST CONFIDENCE ELDERLY (Study at Technical Implementation Unit of Tresna Werdha Social Service of Jombang Regency 2017)}

\begin{abstract}
Self affirmation is technique program self in increase confidence. Confidence is how individuals trusts and believes on the ability of self, order to be able to develop selfawareness reflect positive and independent. The someone elderly shutting out, the passive also emotional behavior, the lack of confidence be the cause of emotion exstreme that can lead to depression, suicide, physical disease and mental.The purpose of this research isanalyze the influence ofself affirmation of confidenceelderly in technicalunit social services tresna werdha jombang. This research using design research method pre experimental with the approach one group pretest - posttest, population this research a number of 70 elderly, from 60 elderly use simple random sampling.Variable independent this research is self affirmation and variable dependent this research is confidence elderly .A measuring instrument that is thequestionnaire, then data processing start editing, coding, scoring and
\end{abstract}


tabulating, andanalyzed use wilcoxon test. The research results show that than 60 elderly before the provision of self affirmation confidence, less 2 elderly ( $3.3 \%$ ), was 30 elderly ( $30 \%$ ), high 28 elderly ( 46,7 \%) and after the provision of self affirmation confidence, less 1 elderly ( $1.7 \%$ ), was 24 elderly (40,0 \%), high 35 elderly ( 58,3\%).Test results wilcoxon 0.0012 which showed that value $p<0.05$ so hl accepted. His conclusion is that there is the influence of self affirmation of confidence elderly in technical unit social services tresna werdha jombang regency.

Keywords: Confidence, elderly, self affirmati

\section{PENDAHULUAN}

Pada lanjut usia banyak permasalahan yang dialami, salah satunya kepercayaan diri kurang. Kepercayaan diri merupakan bagaimana individu percaya dan yakin pada kemampuan diri, sehingga mampu mengembangkan kesadaran diri berfikir positif dan mandiri. Permasalahan kepercayaan diri kurang, muncul di karenakan perubahan psikososial seperti pensiun, indentitas sering dikaitkan dengan peranan pekerjaan, sadar akan kematian, kehilangan hubungan dengan teman-teman dan keluarga, penyakit kronis, perubahan terhadap gambaran diri, kesepian, dan konsep diri (Walgito, 2000 di dalam Herika, 2015, 17).

KEMENKES RI $(2015,29)$ menyebutkan, Indonesia termasuk 5 negara besar dengan jumlah lanjut usia terbanyak di dunia. Pada tahun 2014 penduduk lanjut usia di Indonesia 18,781 juta jiwa dan diperkirakan pada tahun 2025 jumlahnya dapat mencapai 36 juta jiwa. KEMENKES RI (2013) provinsi di Indonesia yang paling banyak penduduk lanjut usia, di Yogyakarta (12,48\%), Jawa Timur $(9,36$ $\%)$, Jawa Tengah (9,26\%), Bali $(8,77 \%)$, Jawa Barat $(7,09 \%)$. Dalam penelitian Mamik (2013) menyebutkan jumlah lansia di Jombang sebesar 113.286 dari jumlah total penduduk 1.209.172 jiwa. Hasil studi pendahuluan di Posyandu Mawar Balong Besuk Utara Desa Balong Besuk Diwek Jombang terdapat 10 yang mengalami penurunan kepercayaan diri, dalam proses wawancara terdapat 4responden menghindari kontak mata, 3 responden tidak banyak bicara, dan 3 responden menjawab secukupnya.
Lanjut usia memiliki kurangnya kemampuan mengepresikan kehangatan dan perasaan terhadap orang lain.Mereka sulit mengungkapkan perasaan pada orang lain karena kurangnya kepercayaan diri, sehingga menyebabkan lansia sering merasa bahwa tindakan yang di lakukan itu sia-sia. Semakin seseorang bersifat introvert, maka perilaku emosional mereka akan ikut menjadi pasif. Kurangnya rasa percaya diri menjadi penyebab emosi exstreme yang dapat mengarah pada depresi, percobaan bunuh diri, penyakit fisik dan mental. Banyak cara untuk meningkatkan rasa kepercayaan diri yaitu, lawan pikiran negatif, terus belajar dari kesalahan dan memperbaikinya, berhenti membanding-bandingkan, kemampuan untuk menambah wawasan dan kemampuan, tampil rapi dan kenakan pakaian yang nyaman dan self affirmation. Self affirmation merupakan suatu teknik pemprograman diri (Permana, 2017, 2).

Kecenderungan semakin meningkatnya lansia merupakan fenomena yang harus diterima dan membutuhkan perhatian dan penanganan dari barbagai pihak agar menjamin kualitas kesejahteraan lansia. Lansia banyak sekali mengalami masalah yang terjadi salah satunya masalah kepercayaan diri. Untuk mengatasi permasalahan kepercayaan diri yang terjadi pada lansia perlu dilakukan terapi self affirmation. Self affirmation merupakan menanamkan mindset dan keyakinan positif dalam bawah sadar, serta membentuk pikiran ulang yang positif. Self affirmation dapat menetralkan respon kecemasan akademik kumulatif diantara mereka yang paling rentan terhadap 
potensi ancaman yang ditimbulkan oleh berbagai kegiatan akademik (Sari, 2012, 2).

\section{METODE PENELITIAN}

Penelitian ini menggunakan rancangan penelitian metode pre eksperimental dengan pendekatan one group prestestposttest(Supardi dan Rustika, 2013, ). Populasi dalam penelitian ini adalah semua lansia yang ada di Unit Pelaksana Teknis Pelayanan Sosial Tresna Werdha Jombang dengan jumlah 70 orang.Pengambilan sampling dalam penelitian ini menggunakansimple random samplingdengan jumlah sampel sebanyak 60 orang. Alat pengumpulan data yang digunakan adalah lembar kuisioner yang sudah diuji validitas dan reliabilitas. Peneliti menggunakan variabel independenyaitu self affirmation dan dependen yaitu kepercayaan diri lansia. Analisa data yang digunakan adalah uji Wilcoxon dengan $\alpha=0,05$.

\section{HASIL PENELITIAN}

\section{Data Umum}

Tabel 1 Distribusi frekuensi berdasarkan jenis kelamin lansia di UPT PSTW Kabupaten Jombang tahun 2017

\begin{tabular}{ccc}
\hline $\begin{array}{c}\text { Jenis } \\
\text { kelamin }\end{array}$ & Frekuensi & Persentase(\%) \\
\hline Laki-laki & 16 & 26,7 \\
Perempuan & 44 & 73,3 \\
\hline Jumlah & 60 & 100 \\
\hline
\end{tabular}

Sumber: Data primer Mei 2017

Berdasarkan datapada tabel1 menunjukkan bahwa sebagian besar lansiadi UPT PSTW Kabupaten Jombangberjenis kelamin perempuan sebanyak44 lansia (73,3\%).

Tabel 2 Distribusi frekuensi berdasarkan pendidikan lansia di UPT PSTW Kabupaten Jombang tahun 2017

\begin{tabular}{ccc}
\hline Pendidikan & $\begin{array}{c}\text { Frekuens Persentase } \\
\text { i }\end{array}$ \\
& 18 & 30 \\
\hline Tidak sekolah & 18 & 5 \\
Tidak tamat sekolah & 3 & 45 \\
Sekolah dasar & 27 & 20 \\
Sekolah menengah & 12 & \\
pertama & & 0 \\
Sekolah menengah & 0 & \\
atas & & 0 \\
Perguruan tinggi & 0 & 100 \\
\hline Jumlah & 60 &
\end{tabular}

Berdasarkan data pada tebel 2 menunjukkan bahwa hampir setengahnya lansiadi UPT PSTW Kabupaten Jombang berpendidikan sekolah dasar sebanyak 27 lansia $(45 \%)$.

Tabel 3 Distribusi frekuensilansia berdasarkan pernah tinggal bersama keluarga di UPT PSTW Kabupaten Jombang tahun 2017

\begin{tabular}{ccc}
\hline $\begin{array}{c}\text { Pernah tinggal } \\
\text { bersama } \\
\text { keluarga }\end{array}$ & Frekuensi & $\begin{array}{c}\text { Persentase } \\
(\%)\end{array}$ \\
\hline Ya & 60 & 100 \\
Tidak & 0 & 0 \\
\hline Jumlah & 60 & 100 \\
\hline Sumber: Data primer Mei 2017 &
\end{tabular}

Berdasarkan data pada tabel 3 menunjukkan bahwaseluruhnya lansia pernah tinggal bersama keluarga sebanyak 60 lansia (100\%).

Tabel 4 Distribusi frekuensi berdasarkanpola asuh orang tua lansia di UPT PSTW Kabupaten Jombang tahun 2017

\begin{tabular}{ccc}
\hline $\begin{array}{c}\text { Pola asuh orang } \\
\text { tua }\end{array}$ & Frekuensi & $\begin{array}{c}\text { Persentase } \\
(\%)\end{array}$ \\
\hline Keras & 25 & 41,7 \\
Bebas & 9 & 15 \\
berpendapat & & \\
Tidak konsisten & 2 & 3,3 \\
Khawatir & 5 & 8,3 \\
berlebihan & & \\
Bebas & 1 & 1,7 \\
Bebas terkontrol & 18 & 30 \\
\hline Jumlah & 60 & 100 \\
\hline Sumber: Data primer Mei 2017 &
\end{tabular}


Berdasarkan data pada tebel 4 menunjukkan bahwahampir setenganhya pola asuh orang tua lansia kerassebanyak 25 lansia(41,7\%).

\section{Data Khusus}

\section{Kepercayaan diri lansia sebelum dilakukan self affirmation}

Tabel5 Distribusi frekuensi berdasarkan kepercayaan diri lansia sebelum (pre test) pemberian self affirmation di UPT PSTW Kabupaten Jombang tahun 2017.

\begin{tabular}{|c|c|c|}
\hline $\begin{array}{l}\text { Kepercayaan } \\
\text { diri (pre test) }\end{array}$ & Frekuensi & $\begin{array}{c}\text { Persentase } \\
(\%)\end{array}$ \\
\hline $\begin{array}{c}\text { Kepercayaan } \\
\text { diri tinggi }\end{array}$ & 28 & 46,7 \\
\hline $\begin{array}{c}\text { Kepercayaan } \\
\text { diri sedang }\end{array}$ & 30 & 50 \\
\hline $\begin{array}{c}\text { Kepercayaan } \\
\text { diri kurang }\end{array}$ & 2 & 3,3 \\
\hline Jumlah & 60 & 100 \\
\hline
\end{tabular}

Berdasarkan data pada tabel 5 menunjukan bahwa tingkat kepercayaan diri lansia sebelum pemberian self affirmation, setenganhya lansia memiliki kepercayaan diri sedang sebanyak 30 lansia (30\%)

\section{Kepercayaan diri lansiasesudah (post test) dilakukan self affirmation}

Tabel 6 distribusi frekuensi berdasarkan kepercayaan diri lansia sesudah (post test) pemberian self affirmation di UPT PSTW Kabupaten Jombang tahun 2017

\begin{tabular}{lcc}
\hline $\begin{array}{l}\text { Keepercayaan } \\
\text { diri (post test) }\end{array}$ & Frekuensi & $\begin{array}{c}\text { Persentase } \\
(\%)\end{array}$ \\
\hline $\begin{array}{l}\text { Kepercayaan } \\
\text { diri tinggi }\end{array}$ & 35 & 58,3 \\
$\begin{array}{l}\text { Kepercayaan } \\
\text { diri sedang }\end{array}$ & 24 & 40,0 \\
$\begin{array}{l}\text { Kepercayaan } \\
\text { diri kurang }\end{array}$ & 1 & 1,7 \\
\hline Jumlah & 60 & 100 \\
\hline Sumber: Data primer Mei 2017
\end{tabular}

Berdasarkan data pada tabel 6 menunjukan bahwa tingkat kepercayaan diri sesudah (post test) pemberian self affirmation, sebagian besar lansia memiliki kepercayaan diri tinggi sebanyak 35 lansia $(58 \%)$

\section{Analisi pengaruh self affirmation terhadap kepercayaan diri lansia}

Tabel 7 Pengaruh self affirmation terhadap kepercayaan diri lansia di UPT PSTW Kabupaten Jombang tahun 2017.

\begin{tabular}{ccccc}
\hline \multirow{2}{*}{$\begin{array}{c}\text { Kepercaya } \\
\text { an diri }\end{array}$} & \multicolumn{2}{c}{ Pretest } & \multicolumn{2}{c}{ Post test } \\
& nsi & Persent & Frekue & Persent \\
ase & nsi & ase(\%) \\
\hline Tinggi & 28 & 46,7 & 35 & 58,3 \\
Sedang & 30 & 50 & 24 & 40,0 \\
Kurang & 2 & 3,3 & 1 & 1,7 \\
Jumlah & 60 & 100 & 60 & 100 \\
\hline \multicolumn{4}{c}{ Uji wilcoxon $\mathrm{p}=0,012$} \\
\hline
\end{tabular}

Berdasarkan data pada tabel 7 menunjukan hasil analisi menggunakan salah satu program komputer yaitu SPSS 16, didapatkan hasil uji Wilcoxon adalah 0,012 hal ini menunjukan bahwa nilai $\mathrm{p}<0,05$ maka $\mathrm{H} 1$ diterima dan $\mathrm{H} 0$ di tolak, atau dengan kata lain ada pengaruh self affirmation terhadap kepercayaan diri lansia di Unit Pelaksana Teknis Pelayanan Sosial Tresna Werdha Kabupaten Jombang tahun 2017.

\section{PEMBAHASAN}

Tingkat kepercayaan diri sebelum dilakukan self affirmation

Berdasarkan data pada tabel 5 menunjukan bahwa tingkat kepercayaan diri sebelum pemberian self affirmation, setengahnya lansia memilikikepercayaan diri sedang sebanyak 30 lansia (30\%). Menurut peneliti kepercayaan diri individu dibentuk sejak kecil, kepercayaan diri dibentuk berawal dari bagaimana pola asuh orang tua mengasuh anaknya serta lingkungan keluarga, hal tersebut akan berpengaruh pada pembentukan kepercayaan diri individu dimasa mendatang. Kepercayaan diri akan terbentuk dengan baik dan tinggi apabila dimasa kecil individu mendapatkan 
pola asuh orang tua yang baik serta lingkungan keluarga yang baik. Setelah dari pola asuh orang tua dan lingkungan keluarga, pendidikan akan menambah kepercayaan diri individu dari informasi dan pengetahuan yang didapatkan dimasa pendidikan. Pada masa pendidikan kepercayaan diri individu akan di bentuk menjadi lebih baik. Individu yang memiliki pendidikan tinggi cenderung memiliki kepercayaan diri lebih tinggi daripada yang memiliki pendidikan rendah. Individu yang memiliki percaya diri tinggi dapat dilihat dari bagaimana individu mencintai dirinya sendiri, memahami dirinya sendiri, memiliki tujuan hidup yang jelas dan berfikir positif. Kepercayaan diri dapat dipengaruhi beberapa faktor yaitu, jenis kelamin, pendidikan, lingkungan keluarga,dan pola asuh orang tua. Faktor tersebut akan berdampak pada pembentukan kepercayaan diri individu dimasa mendatang. Beberapa faktor yang mempengaruhi kepercayaan diri, jenis kelamin, pendidikan, lingkungan keluarga, pola asuh orang tua (Tholib, 2015, 3).

Berdasarkan data pada tabel 1 menunjukkan bahwa sebagian besar lansia di UPT PSTW Kabupaten Jombang berjenis kelamin perempuan sebanyak 44 lansia (73,3\%).Menurut peneliti jenis kelamin mempengaruhikepercayaan diri, karena konsep diri atau pandangan dan sikap seseorang terhadap dirinya sendiri antara laki-laki dan perempuan ditanamkan berbeda sejak dari kecil, laki-laki lebih diperlalukan tegas daripada perempuan, dikarenakan laki-laki merupakan seorang pemimpin, sehingga akan membentuk kepercayaan diri berbeda antara laki-laki dengan perempuan.Perbedaan biologis antara laki-laki dan perempuan menentukan peran masing-masing sesuai jenis kelaminya. Perlakuan orang tua dalam keluarga yang membeda-bedakan antara laki-laki dan perempuan merupakan awal mula perbedaan dalam pembentukan konsep diri bagi seseorang, konsep diri ini akan membawa pengaruh yang besar pada pembentukan rasa percaya diri (Marbun, 2013, 1).
Berdasarkan datapada tabel 2 menunjukkan bahwa hampirsetenganhya lansia di UPT PSTW Kabupaten Jombang berpendidikan Sekolah Dasar sebanyak 27 lansia (45\%). Menurut peneliti pendidikan mempengaruhi kepercayaan diri, karena individu yang berpendidikan memiliki lebih banyak pengetahuan sehingga mampu dalam menata diri. Individu yang berpendidikan rendah lebih rentan terhadap kurang nya kepercayaan diri, dikarenakan kurang nya pengetahuan dalam menghadapi atau menyelesaikan masalah yang dapat mempengaruhi pembentukan kepercayaan diri. Jenjang pendidikan yang rendah akan membuat seseorang merasa tidak lebih baik dari pada seseorang yang pendidikannya lebih tinggi begitupula sebaliknya, seseorang yang memiliki kepercayaan diri dapat mencukupi kebutuhannya dan kekuatannya dalam mencerminkan kondisi secara nyata (Tholib, 2015, 3).

Berdasarkan data pada tabel 3 menunjukkan bahwa seluruhnya lansia pernah tinggal bersama keluarga sebanyak 60 lansia $(100 \%)$. Menurut peneliti lingkungan keluarga mempengaruhi kepercayaan diri, karena lingkungan keluarga yang buruk akan menimbulkan sifat dan watak yang buruk, sedangkan lingkungan keluarga yang baik akan menimbulkan sifat dan watak yang baik, karenalingkungan keluarga memberikan rasa aman, nyaman, dan tentram, individu yang pernah tinggal bersama keluarga akan mendapatkan rasa tersebut dan membentuk kepercayaan diri yang tinggi. Motivasi dari lingkungan keluarga yang baik dengan cara saling menjaga komunikasi akan memberikan dampak yang positif yaitu kenyamanaan dan percaya diri secara optimal(Tholib, 2015, 4).

Berdasarkan datapada tabel 4 menunjukkan bahwa hampirsetengahnya pola asuh orang tua lansia keras sebanyak 25 lansia $(41,7 \%)$. Menurut peneliti pola asuh orang tua mempengaruhi kepercayaan diri, karena pola asuh memiliki peran penting dalam perkembangan sifat dan perilaku moral pada individu. Pola asuh 
yang diberikan orang tua, akan menjadi dasar pembentukan sifat dan prilaku moral individu serta berdampakdimasa mendatang dalam menghadapi atau menyelesaikan suatu masalah. Pola asuh yang diberikan oleh orang tua kepada anak dalam keluarga merupakan faktor utama yang besar pengaruhnya bagi perkembangan individu pada masa yang akan datang (Marbun, 2013, 4).

\section{Tingkat kepercayaan diri sesudah dilakukan self affirmation}

Berdasarkan datapada tabel 6 menunjukan bahwa tingkat kepercayaan diri sesudah (post test) pemberian self affirmation, sebagian besar lansia memiliki kepercayaan diri tinggi sebanyak 35 lansia (58\%). Menurut peniliti kepercayaan diri meningkat setelah dilakukanya self affirmation, karena Self affirmation menanamkan keyakinan positif dalam bawah sadar, serta membentuk pikiran ulang yang positif dan mengganti pola pikir yang negatif sehingga dapat meningkatkan kepercayaan diri. Self affirmation merupakan teknik pemprograman diri yang luar biasa, bila digunakan dengan benar dan kondisi yang tepat (Sembiring, 2014, 2).

Self affirmation atau penegasan diri merupakan pernyataan positif atau kalimat yang ditujukan untuk diri sendiri yang bisa mempengaruhi pikiran bawah sadar untuk membantu anda mengembangkan persepsi yang lebih positif terhadap diri sendiri. Self affirmation bisa membantu mengubah prilaku yang merugikan dan meningkatkan kepercayaan diri, dengan proses menanamkan ide atau kata-kata yang diinginkan, secara tulisan atau lisan dilakukan berulang-ulang, pada kondisi gelombang otak alpha atau rileks, dalam gelombang ini ide akan mudah diterima oleh alam bawah sadar. Hal ini sejalan dengan penelitian yang dilakukanSari (2012, 27) Self affirmation dapat menetralkan respon kecemasan akademik kumulatif diantara mereka yang paling rentan terhadap potensi ancaman yang ditimbulkan oleh berbagai kegiatan akademik.

\section{Pengaruh self affirmation tehadap kepercayaan diri lansia}

Berdasarkan data pada tabel 7 menunjukan hasil analisi menggunakan salah satu program komputer yaitu SPSS 16, didapatkan hasil uji Wilcoxon adalah 0,012 hal ini menunjukan bahwa nilai $\mathrm{p}<0,05$ maka H1 diterima dan H0ditolak, atau dengan kata lain ada pengaruh self affirmation terhadap kepercayaan diri lansia di Unit Pelaksana Teknis Pelayanan Sosial Tresna Werdha Kabupaten Jombang tahun 2017. Menurut peniliti self affirmation mempengaruhi kepercayaan diri lansia, karena self affirmation dapat memprogram diri dan membentuk pikiran ulang yang positif. Self affirmation berkerja dengan cara menyingkirkan dan menggantikan perintah-perintah negatif yang telah terlanjur terkirim kealam bawah sadar, self affirmation akan membentuk program baru di alam bawah sadar yang lebih baik, karena apa yang diucapkan dan dipikirkan akan diprogram dalam pikiran bawah sadar. Self affirmationmerupakan teknik untuk penguatan keyakinan, tentang cara menanamkan mindset dan keyakinan positif dalam bawah sadar (Antariksa, 2012, 2).Kepercayaan diri merupakan suatu keyakinan dan kemampuan diri dalam kehidupan seseorang untuk menerima kenyataan, sehingga mampu mengembangkan kesadaran diri berfikir positif dan mandiri (Walgito, 2008 didalam Herika, 2015, 22).

\section{KESIMPULAN DAN SARAN}

\section{KESIMPULAN}

Dari hasil penelitian yang sudah dilakukan dapat disimpulkan sebagai berikut:

1. Tingkat kepercayaan diri sebelum dilakukan self affirmation diperoleh hasil yaitu setengahnya lansia memiliki kepercayaan diri sedang di Unit 
Pelaksana Teknis Pelayanan Sosial Tresna Werdha Kabupaten Jombang.

2. Tingkat kepercayaan diri sesudah dilakukan self affirmation diperoleh hasil yaitu sebagian besar lansia memiliki kepercayaan diri tinggi di Unit Pelaksana Teknis Pelayanan Sosial Tresna Werdha Kabupaten Jombang.

3. Ada pengaruh self affirmation terhadap kepercayaan diri lansia di Unit Pelaksana Teknis Pelayanan Sosial Tresna Werdha Kabupaten Jombang

\section{SARAN}

Adapun saran yang diberikan oleh peneliti sebagai berikut:

1. Bagi Lansia

Diharapkan lanisa mampu menggunakan self affirmation dalam meningkatkan kepercayaan dirinya, Karena self affirmation sangat mudah untuk dilakukan tanpa memerlukan waktu yang sangat lama.

2. Bagi petugas kesehatan panti (Perawat panti)

Diharapkan petugas perawat panti dapat memberikan teknik self affirmation untuk menambah kepercayaan diri lansia agar lansia tetap mandiri, tidak mementingkan diri sendiri, toleran, optimis dengan kelebihan dan kekurangan yang dimilki.

3. Bagi peneliti selanjutnya

Diharapkan peneliti selanjutnya dapat menjadikan penelitian ini sabagai rujukan dan sumber informasi serta dapat membandingan efektifitas berbagai bentuk teknik non farmakologis lainya dalam meningkatkan kepercayaan diri.

\section{DAFTAR PUSTAKA}

Antariksa Yodhia. (2012) Self Affirmation dan Positive Visualization What You Think Is What You get. (http://strategimanajemen.net/2012/12 /17/positive-affirmation-what-youthink-is-what-you-get/), disitasi: 22 maret 2017

Herika Dewi. (2015) Perbedaan Tingkat Kepercayaan Diri antara Ayah dan Ibu yang memiliki Anak Tunagrahita. Tesis, Universitas Islam Negeri Sultan Syarif Kasim, Riau.

Kementrian Kesehatana Republik Indonesia (2013) Riset Kesehatan Dasar.

(http://www.depkes.go.id/resources/d ownload/general/Hasil\%20Riskesdas \%202013), disitasi: 3 maret 2017

Kementrian Kesehatan Republik Indonesia. (2015) Pelayanan damPeningkatan Kesehatan Usia Lanjut.

(http://www.depkes.go.id/article/view /15052700010/pelayanan-danpeningkatan-kesehatan-usialanjut.html),disitasi: 30 maret 2017

Mamik R. (2013) Hubunganantara Pengetahuan dengan Keaktifan Lansia datang ke Posyandu Lansia. STIKES Pemkab Jombang, (https://www.google.co.id/url?sa=t\&r

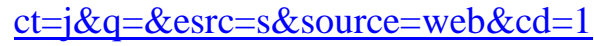
$\underline{\text { cad }}=$ rja\&uact $=8 \& v e d=0$ ahUKEwj 1 gbfy0f3SAhWLiLwKHQbsD3wQFgg ZMAA\&url=http\%3A\%2F\%2Fstikes pemkabjombang.ac.id\%2Fejurnal\%2F index.php\%2FJuli2013\%2Farticle\%2 Fdownload\%2F28\%2F46\&usg=AFQj CNHP1U35b3Ks2LyOntOajTg6GVxj PA\&sig2=haTPEU26Kj68cj10sygyO g\&bvm=bv.151325232,d.dGc), disitasi: 30 maret 2017

Marbun Janri Riko. (2013) Kepercayaan diri.(http://haluangwanasatria.blogspo t.co.id/2013/02/kepercayaandiri_25.html), disitasi : 2 Juli 2017 
Permana Dadan Eka.(2017) 5 Cara Meningkatkan Kepercayaan Diri. (http://www.bintang.com/success/read /2823689/5-cara-meningkatkankepercayaan-diri), disitasi: 7 Mei 2017

Sari Ela Nurlaela.(2012) Melalui Teknik Self Affirmation. UPI Bandung, (http://antologi.upi.edu/file/ELA NU RLAELA_SARI.pdf), disitasi : 30 maret 2017

Sembiring Ronald.(2014) Teknik Pemprograman Diri yang Jauh Lebih Powerful dari Afirmasi. (https://aquariuslearning.co.id/teknikpemprograman-diri/), disitasi: $7 \mathrm{Mei}$ 2017

Supardi Sudibyo\& Rustika. (2013)Metodologi Riset Keperawatan.Ed.1. CV TRANS INFO MEDIA. Yogyakarta

Tholib Abu. (2015) Mengembangkan kepercayaan diri. (http://tholibpoenya.blogspot.co.id/20 15/01/makalah-mengembangkankepercayaan-diri.html), disitasi: 2 Juli 2017 